\title{
Multiplicity, Audibility, and Musical Continuity
}

\author{
PETER ALWARD University of Saskatchewan
}

\begin{abstract}
Musical works are both multiple - they have a plurality of instances - and audible - they can be heard by listening to their instances. Two prominent approaches to musical ontology designed to explain these features of musical works are the typetoken model and the continuant-stage model. Julian Dodd has argued that the typetoken model has an advantage over the continuant-stage model because it can offer a direct explanation of the audibility of musical works in terms of their ontological category. In this paper, I defend the continuant-stage model against Dodd's argument by invoking a work-unifying continuity relation.
\end{abstract}

RÉSUMÉ : Les æuvres musicales sont à la fois multiples et audibles. Dans le domaine de l'ontologie musicale, deux des principaux modèles conçus pour expliquer ces caractéristiques des cuvres musicales sont le modèle type/instanciation (type-token model) et le modèle étape/continuité (continuant-stage model). Julian Dodd a soutenu que le modèle type/instanciation a un avantage sur le modèle étape/continuité, car il peut offrir une explication directe de l'audibilité des œuvres musicales en termes de catégorie ontologique. Je défends le modèle étape/continuité contre l'argument de Dodd en invoquant une relation de continuité qui unifie l'œuvre.

Keywords: music, ontology, multiplicity, audibility, types, continuants

\section{Introduction}

Musical multiplicity is a familiar and much discussed phenomenon in the literature on musical ontology. The basic idea is that musical works have a plurality of instances - most prominently performances - that cannot in general be

Dialogue 59 (2020), 101-121

(C) Canadian Philosophical Association/Association canadienne de philosophie 2020 doi:10.1017/S0012217320000074 
identified with the works themselves. Two prominent approaches to musical ontology — the type-token model and the continuant-stage model — are largely designed to explain musical multiplicity. Musical audibility is also a familiar phenomenon, but one that has garnered somewhat less discussion. It consists in the ability of appreciators to hear a musical work by means of listening to any one of its (correctly formed) instances. Julian Dodd has argued that, while the type-token model has a simple and principled explanation of musical audibility, the continuant-stage model does not. In this paper, I argue that Dodd is wrong on this point. In particular, I develop a continuity relation involving musical instances - which lies at the core of the continuant-stage model and argue that it yields an explanation of musical audibility at least as strong as that available to the type-token model.

This paper consists of three central parts. First, musical multiplicity is developed and the type-token and continuant-stage models of it are introduced. Second, musical audibility is considered and Dodd's objection to the continuant-stage model, which invokes it, is presented. And, third, the continuity relation at the core of the continuant-stage model is motivated and developed, and an argument that it yields an adequate explanation of audibility is defended.

\section{Musical Multiplicity}

\subsection{The Nature of Multiplicity}

Musical works are commonly thought to be multiple. ${ }^{1}$ A first gloss on this idea is as follows. In some art forms - painting, for example — an artwork can be more or less unproblematically identified with a particular physical object, at least insofar as the object is conceived of in the right way or, perhaps, situated in the right kind of social practice. But just as in literature there are multiple physical books by means of which someone can read a novel, in music there are multiple performances by means of which an appreciator can hear a musical

1 A notable exception is Mag Uidhir (2013, p. 179), who takes musical works to be concrete singular entities that (potentially) stand in relations of relevant similarity to other concrete singular musical works. It is also worth noting that, in the Western classical tradition, musical works are normally identified with compositions - the products of musical compositional activity. Musical multiplicity, however, is not specific to this tradition but can be found in a broader range of genres, including rock and jazz, among others. And the identification of works with compositions in these other genres is controversial. It has been argued, for example, that in rock music works should instead be identified with recordings (Kania, 2006); and it has been argued that in jazz they should be identified with performances (Alperson, 1984). And, if this is right, even if jazz and rock compositions are multiple in the relevant sense, jazz and rock works might not be. Nevertheless, in this paper, I will follow the convention of formulating the issue in terms of works. 
work. ${ }^{2}$ And just as a novel cannot be identified with any one of its corresponding books, a musical work cannot be identified with any one of its performances. After all, a musical work will continue to exist after any particular performance of it comes to an end.

There are two preliminary adjustments to this characterization of the distinction between multiple and singular artworks worth making at this point. First, the distinction needs to be defined modally rather than extensionally: what makes an artwork multiple is not that it in fact has multiple instances, but that it could have multiple instances. ${ }^{3}$ Even a never performed musical work is multiple as long as it could have been performed on more than one occasion. ${ }^{4}$ Second, following Stephen Davies, we can distinguish among three ways in which multiple artworks can be created: by producing exemplars, encodings, or instructions. ${ }^{5}$ In the first case, an artist creates a multiple artwork by producing an exemplar, an instance of it that serves as a (normative) model for other instances. For example, an author might create a novel by producing a manuscript, which other instances of it must resemble in relevant respects. In the case of encoding, an artist creates a multiple artwork by creating an artifact that is not itself an instance of the artwork, but that can be decoded to produce instances of the work. For example, a photographer might produce a photographic work by creating a negative from which instances of the work can be produced using various chemical processes. In the third case, an artist creates an artwork by producing a set of instructions for the generation of instances of the work. For example, a playwright might create a play by writing a script - a set of instructions for producing performances of the play. The distinction is important for present purposes because musical works can, at least arguably, be created by each of these means: in addition to creating a musical work by writing a score, a musician could also do so by means of an initial performance or by producing a recording. ${ }^{6}$

It is worth noting that the distinction between singular and multiple artworks has not been undisputed. Gregory Currie, for example, has argued that all artworks are, in principle, multiple by appealing to a hypothetical supercopier capable of producing molecule for molecule duplicates of artworks. ${ }^{7}$ If, for example, Currie's supercopier were used to duplicate Robert Rauschenberg's

2 An appreciator can also hear a musical work by listening to a recording of it. For present purposes, I will focus on appreciators' experiences of performances.

3 See Stephen Davies (2003, p. 158); David Davies (2010, p. 411).

4 For a discussion of the status of unperformable works, see Cray (2016).

5 Stephen Davies (2003, pp. 159-163).

6 If these are to be independent methods of creating musical works, neither the initial performance nor the recording can be based on a prior score; and, for similar reasons, a work-generating recording cannot be of a performance.

7 Currie (1989, pp. 110-111). 
Erased de Kooning, the supercopy would serve just as well for the aesthetic appreciation of Rauschenberg's work as would the original, at least when coupled with knowledge of the original's (in contrast to the duplicate's) causal origin. ${ }^{8}$ Davies concedes that a supercopy of an artwork might be an "invaluable substitute" for it - at least for those appreciators without access to the original - but argues that that does not suffice to make the supercopy an instance of the work as opposed to a copy of it. ${ }^{9}$ And Davies endorses a kind of institutional theory governing whether an artwork is singular or multiple and, if the latter, whether a given product is an instance or copy of it: "[it] is only within the context of an art practice and tradition that artists can formulate the kinds of intentions that establish, for example, whether a given product is a singular piece or, instead, is an exemplar that provides the model for further work instances." 10

David Davies, however, rejects Stephen Davies' defence of the distinction between singular and multiple artworks. In particular, he argues that the distinction between instances and copies cannot secure the distinction between multiple and singular artworks both because there are no "... firm differences between 'copies' and 'instances' ... in our ordinary talk about painting ..." and because talk of instances is itself ambiguous between Provenential Instances, or P-Instances, and Epistemic Instances, or E-Instances. ${ }^{11}$ The P-Instances of an artwork, according to David Davies, are those manifestations of it that stand in the right kind of causal-intentional relation to the work's "history of making." 12 In the case of artworks created by producing sets of instructions, the P-Instances are those manifestations generated by following the instructions. In the case of artworks created by encoding, the P-Instances are those manifestations generated by the requisite process of decoding. And, in case of artworks created by producing an exemplar, the exemplars themselves are the sole P-Instances. As a result, works of art created by encoding or instructions are P-multiple, whereas those created by exemplars are P-singular. ${ }^{13}$ The E-Instances of an artwork, in contrast, are those objects or events that possess the requisite properties to yield “... the experiential engagement necessary for proper appreciation ..." of the artwork regardless of the historical processes by which they came to acquire these properties. ${ }^{14}$ So, for example, the E-Instances of a painting would be canvasses that possess the right patterns of colours and shapes; and the E-Instances of a novel would be books that

\footnotetext{
8 Stephen Davies (2003, p. 157).

9 Stephen Davies (2003, p. 157).

10 Stephen Davies (2003, p. 159).

11 David Davies (2010, pp. 417-418).

12 David Davies (2010, p. 414).

13 David Davies (2010, pp. 413-414).

14 David Davies (2010, p. 415).
} 
possess the right sequences of words. ${ }^{15}$ Moreover, Davies argues that all artworks are, in principle, E-multiple except works whose proper appreciation “... requires that we experientially engage with the very history ..." of their making. ${ }^{16}$ The upshot is that, contra Stephen Davies, there is a perfectly good sense in which (nearly) all artworks are multiple - E-multiplicity; but, at the same time, there is another perfectly good sense in which at least some artworks are singular — P-singularity.

I have no qualms about David Davies' claims regarding the E-multiplicity of (nearly) all artworks. But there are a number of overlapping reasons to balk at his reconstruction of the distinction between singular and multiple artworks in terms of P-singularity and P-multiplicity. First, the reconstructed distinction sorts artworks differently than the original. According to the original distinction, novels count as multiple artworks with their various copies as instances; but, insofar as novels are created by producing exemplars - original manuscripts — they are P-singular. ${ }^{17}$ Second, the reconstructed distinction blurs the significance of the distinction between copies of novels and copies of paintings. As a matter of fact, when one reads a copy of the manuscript by means of which a novel is created, one reads the novel itself; but when one looks at a copy of a painting, one experiences only a (perhaps illuminating) substitute for the painting and not the painting itself. But, on Davies' analysis, although both sorts of copies are distinguished from other E-Instances by standing in certain sorts of causal relations to the histories of their corresponding works, neither count as P-Instances in their own right. Of course, someone might insist that, when we experience a copy of a painting that counts as a proper E-Instance of it, we legitimately experience the painting itself because we experience an epistemic analogue of it that wholly conveys all of the painting's aesthetically relevant properties. ${ }^{18}$ But suppose a painting has been destroyed and only a copy, which counts as a proper E-Instance of it, remains. Our experience of the copy might well convey all of the original painting's aesthetically relevant properties, but in a perfectly good sense we have not thereby directly experienced the painting itself. And it is in this sense that our experiences of copies of novels and copies of paintings differ. Third and most important for present purposes, the reconstructed distinction entails that musical works constitute a motley category, with those created by encoding or instructions counting as P-multiple and those created by exemplar counting as P-singular. Now Davies does seem to be committed to the P-multiplicity of musical works: “... in the examples examined thus far — painting, music, and photography — works are P-multiple (or P-singular) just in case they are treated in our practice as being

\footnotetext{
15 David Davies (2010, p. 415).

16 David Davies (2010, p. 426).

17 David Davies (2010, p. 416).

18 This worry comes from an anonymous referee for Dialogue.
} 
E-multiple (or E-singular)." ${ }^{19}$ But he also seems committed to the P-singularity of works created by exemplar: “... a literary work such as Gravity's Rainbow is P-singular and E-multiple, if, as has been suggested, literary works come into existence through the production of an exemplar ....,20 As a result, insofar as Stephen Davies is correct that musical works can be created through the production of exemplars, Davies does seem to be faced with a potential inconsistency on this point. One might attempt to defang the whole motely category worry by pointing out that music really does seem like a pretty motley collection of practices, including things as diverse as pure instrumental classical music and punk rock songs, and varying in respect of whether or not they are performed, recorded, or even scored. We might, therefore, expect slightly different treatments for each of these practices, rather than a grand, unifying theory. ${ }^{21}$ But not only does the distinction between multiple and singular artworks seem to be substantial rather than slight, insofar as works within a single genre can be produced both by score and by exemplar, it could turn out that otherwise similar musical works fall into very different ontological categories.

Short of simply conceding that musical works created by producing an exemplar fall into a distinct ontological category than those created by means of a score - or denying that musical works can be created by means of producing exemplars at all - there seem to be two central strategies for resolving these worries. First, one might attempt to refine Davies' account of P-Instances so that works created by exemplar count as P-multiple rather than P-singular. Presumably, this would involve the specification of some kind of causal-intentional relation that holds between work-generating exemplars and those manifestations that count (alongside the exemplars themselves) as P-Instances of those works. The challenge for this strategy is to come up with a principled account of the causal-intentional relation such that performances of musical works are so related to work-generating exemplars - and copies of novels are so related to work-generating manuscripts - but copies of paintings are not so related to their originals.

Alternately, one might introduce a third category of instances, Identity Instances or I-Instances. As the name suggests, the I-Instances of an artwork are those manifestations of it that are connected to the identity of the artwork in the right way. There are two characteristic features of I-Instances: an appreciator can experience the artwork itself by means of experiencing its I-Instances; and the existence of an I-Instance at a time, $t$, is by itself sufficient for the existence of the corresponding artwork at t. Consider again Rauschenberg's Erased de Kooning. The experience of a supercopy of it might well yield "... the experiential engagement necessary for proper appreciation ..." of the painting, but it

\footnotetext{
19 David Davies (2010, p. 416).

20 David Davies (2010, p. 416).

21 This worry comes from an anonymous referee for Dialogue.
} 
would not count as an experience of the work itself. Moreover, if the original was destroyed and only the supercopy remained, we would not, on that basis, say that Erased de Kooning still existed. As a result, the supercopy does not count as an I-Instance of the painting. Consider, in contrast, Anthony Trollope's Barchester Towers. By reading a (sufficiently accurate) copy of it, one would thereby read the novel itself; and, even if it was the only copy left, Barchester Towers would still exist. As a result, the copy would count as an I-Instance of the novel. ${ }^{22}$ And we can reconstruct the distinction between singular and multiple artworks in terms of I-singularity and I-multiplicity, where an artwork is I-multiple if it could have multiple I-Instances and I-singular if it could have only one I-Instance. One might worry that this appeal to I-Instances presupposes an account of the identity conditions of artworks, whereas one might have expected to deploy the relevant notion of art instances in an account of such identity conditions. ${ }^{23}$ But no such presupposition is made here. Rather, all that is required is conformity to (sufficiently widely shared) identity judgements in the relevant critical and appreciative practices. The reason a copy of Barchester Towers counts as an I-Instance of the novel is because it follows from the identity judgements made in literary practices that it is so. And the reason that a supercopy of Erased de Kooning does not count as an I-Instance of the painting is because it follows from the identity judgements made in painting practices that it is not.

In what follows, I will adopt the second strategy and formulate things in terms of I-Instances. Not only does this sort singular and multiple artworks in the right way - counting novels as multiple, rather than singular — it clears the way for a uniform account of musical works as multiple artworks, including those created by exemplar. It is worth noting, however, that if Davies' account were successfully refined as per the first strategy sketched above, the issues here could just as well be formulated in terms of P-Instances and P-multiplicity. The main difficulty with Davies' unrefined account is that it does not include any instances of works created by means of exemplars among the P-Instances of those works. But the proposed refinements would arguably render the class of P-Instances and the class of I-Instances coextensive. Finally, it is worth emphasizing that the issues here cannot be adequately formulated in terms of E-Instances, even if they yield all the experiences required for a proper appreciation of their corresponding artworks. The central concern of this paper is with the nature of musical works themselves. Even if a performance of another work - or a sound event that is a performance of no work at all — yields insight into a given work, it does not follow that the performance should be incorporated

22 Following Stephen Davies, I endorse a kind of institutional theory here, according to which the status of manifestations of artworks as I-Instances depends on the practices and traditions of the artforms into which the various works fall.

This worry comes from an anonymous referee for Dialogue. 
into account of the nature of that work. Suppose, by way analogy, that a person, Jane, has a super-doppelganger, Jane $\mathrm{SD}_{\mathrm{S}}$ - who is a molecule for molecule

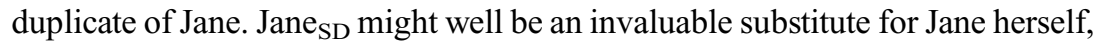
yielding the experiential engagement necessary for proper appreciation of the latter. But it would be a mistake to incorporate Jane ${ }_{\mathrm{SD}}$ into an account of the nature of Jane - perhaps by taking Jane herself to be a type and Jane SD $_{\text {to }}$ be one of her tokens - on this basis.

\subsection{Models of Multiplicity}

In this section, two models of the I-multiplicity of musical works will be considered: the type-token model and the continuant-stage model. In its simplest form, the type-token model takes musical works to be types and the I-Instances of works to be tokens of those types. More precisely, a musical work is a sound-pattern type - a pattern or arrangement of particular sound types - and a concrete sound event counts as an I-Instance of a given work only if it consists of tokens of the individual sound types occurring in the requisite pattern. ${ }^{24}$ For example, according to the type-token model, Neil Young's Rockin' in the Free World is a sound-pattern type consisting of combinations of abstract sound types arranged in a certain order, and Young's Rockin' in the Free World performance on October 18, 2008 in Regina, Saskatchewan counts as an I-Instance of this work because it consisted in the production of tokens of the relevant sound types in the appropriate pattern. Note: exactly which soundpattern type is identified with a given musical work depends, in part, on the exemplar, encoding, or instructions by means of which the work was created, but also upon such things as notational and performance practices, genre conventions, and various sorts of listening practices. ${ }^{25}$

There are more complex variants of the type-token model, which deviate from the simple model sketched above in a number of different dimensions. First, rather than identifying musical works with structured sound types, some views take them to be more complex entities, which include soundpattern types as constituents. According to Jerrold Levinson's indicated-type theory, for example, musical works are complex entities made up of - or, more modestly, individuated in terms of - structural types, composers, and times. ${ }^{26}$ Second, some views have additional - or alternate - conditions that need to be satisfied in order for a sound event to count as an I-Instance of a given work. Typically, this involves the requirement that the sound event stand in the right kind of causal or intentional relationship to the work. For example, rather than requiring a sound event to be a token of the type identified with a work, Levinson requires instead that it be

\footnotetext{
24 See, e.g., Dodd (2002); Kivy (1983).

25 Stephen Davies (2003, pp. 159-163).

26 Levinson (1980).
} 
intended to be a token of this type and that this intention "succeed to a reasonable degree."27

A number of reasons have been offered for balking at the type-token model. Ben Caplan and Carl Matheson, for example, have argued that it incorporates an unpalatable ontology of Platonic entities. ${ }^{28}$ Guy Rohrbaugh has argued that it is incompatible with the temporal flexibility of musical works - the thesis that musical compositions can change their properties over time. ${ }^{29}$ And I have argued that it is incompatible with the fact that musical works are created and not discovered. ${ }^{30}$ Advocates of the type-token model have contested all of these charges and the issues they raise remain unsettled. ${ }^{31}$ Nevertheless, such considerations have motivated the development of the alternative continuantstage model. According to this model, musical works are continuants: entities that persist through time. I-Instances are stages in the histories of musical continuants or, perhaps, temporal stages of the continuants themselves. In its most basic form, the continuant-stage model takes musical works to consist of temporally ordered sequences of I-Instances (and, perhaps, the exemplars, encodings, or instructions by means of which the works were composed as well); and a particular sound event counts as an I-Instance of a given musical work only if it is a member of the corresponding sequence. So, for example, Rockin' in the Free World consists of a temporally ordered sequence of I-Instances, and Young's performance of it on October 18, 2008 in Regina, Saskatchewan counts as an I-Instance of this work because it is one of the performances in this sequence.

More developed versions of the continuant-stage model offer a more robust account the constitutive relation between musical continuants and their I-Instances. According to the mereological account, for example, I-Instances are literally parts of musical continuants and the continuants themselves are fusions or mereological sums of their I-Instances. ${ }^{32}$ According to the historical individual account, in contrast, musical works are modally flexible, temporally flexible, and temporal 'higher level' entities - dependent on but not constituted by their I-Instances. ${ }^{33}$ And, according to the common currency view, musical

\footnotetext{
27 Levinson (1980, p. 24).

28 Caplan and Matheson (2006). See also Tillman (2011).

29 Rohrbaugh (2003, p. 178).

30 Alward (2004, pp. 331-332).

31 Kania (2013, pp. 209-210) argues that a Platonic ontology is required for a realist account of musical works; Dodd (2004, p. 347) argues that the type-token model is compatible with musical flexibility; and Levinson (1980) defends a version of the type-token model that is designed, in part, to be consistent with the creation of musical works. See also Friedell (forthcoming).

32 Caplan and Matheson (2006); Tillman (2011).

33 Rohrbaugh (2003, pp. 198-199).
} 
works are complex events consisting of networks of causally related I-Instances. ${ }^{34}$ But all these views presuppose an answer to the question of exactly which sound events count as I-Instances of which musical works. After all, before we can adjudicate whether an I-Instance is a part or causal node of, or stands in a dependence relation to, a musical work, we need to know exactly which musical work it is a part or node of, or is dependent on it. On the continuant-stage model, the answer to this question is given by a continuity relation, a relation in which the I-Instances of a given musical work stand to the exemplar, encoding, or set of instructions by means of which it was composed. And, as we shall see below, it is this very same continuity relation that resolves Dodd's audibility objection to the continuant-stage model.

\section{Musical Audibility}

\subsection{Audibility and Default Status}

In addition to multiplicity, another central feature of musical works is their audibility. To say that a musical work is audible is to say that, by means of listening to a performance or playing of a recording that counts as one if its I-Instances, one thereby listens to the work itself. ${ }^{35}$ Moreover, according to Dodd, the reason an appreciator can hear a musical work by listening to one of its I-Instances is that the work is in some sense present in the I-Instance: "each such datable, locatable performance or playing is an occurrence of it: an item in which the work itself is somehow present, and which thereby makes the work manifest to an audience." 36 Consider, for example, an appreciator who listens to Young's performance of Rockin' in the Free World on October 18, 2008 in Regina, Saskatchewan. Not only does the appreciator hear the performance of Rockin' in the Free World in question, she also hears the work Rockin' in the Free World itself. Moreover, she hears the work by means of hearing the performance in Regina; and, according to Dodd, this is because the work Rockin' in the Free World is present in the Regina performance, as well as in the performance of it on April 15, 2009 in Lethbridge, Alberta.

Dodd argues that the phenomenon of musical audibility counts in favour of the type-token model and against the continuant-stage model. First, he argues that the explanation the type-token model offers of audibility - as well as of I-multiplicity — gives it a kind of default status vis-à-vis the question of musical

34 Alward (2004, p. 335). This label is borrowed from Kaplan (1990). The common currency conception has frequently been mischaracterized as a version of the mereological approach (see, e.g., Aliyev, 2017, p. 86; Caplan and Matheson, 2006, p. 60, n. 7; Tillman, 2011, p. 16, n. 11); after all, although it is arguably true that musical I-Instances are parts of musical continuants on the common currency conception, it is not true, on this view, that musical continuants are fusions of their I-Instances.

Dodd (2007, p. 11).

36

Dodd (2008, p. 1113). 
ontology: "[it] is because one prominent kind of ontological proposal — the type/token theory - answers this question so elegantly that it has assumed a hegemonic position on the categorical issue." ${ }^{37}$ Dodd's reasoning here is twofold: the audibility of musical works is best explained in terms of the ontological category to which they belong, that is, in terms of their membership in " ... an ontological category for which being capable of having occurrences is built in as standard ..."38; and taking musical works to be types is the most "natural" way to generate a direct explanation of their audibility in terms of their ontological category. ${ }^{39}$ After all, when one listens to a token of a musical type, “... [the] token stands proxy for the type, and thereby enables one's perceptual experience to 'pass through' the token, and so relate the listener to the type lying behind it." 40

Second, Dodd argues that, insofar as musical works are taken to be continuants rather than types, no direct explanation of their audibility in terms of their ontological category is forthcoming. After all, it is not in general true that the stages of a continuant count as occurrences, in Dodd's sense, of it: for example, “... the fifth minute of the 1975 Cup Final is a temporal part of the match, but this temporal part is not an occurrence of the match." 41 As a result, the continuant-stage requires an extra-categorical explanation of the audibility of musical works. And any such explanation not only runs the risk of ontological profligacy, it may also face the charge of being ad hoc. ${ }^{42}$ Moreover, even if some such explanation of audibility can be found, it will remain inferior to the direct explanation in terms of the ontological category of types.

\subsection{A Faulty Default}

David Davies has argued that Dodd's claim of a default status for the type-token model, grounded in musical audibility, is ill-founded. ${ }^{43}$ Davies' argument draws on the details of Dodd's account of musical types. According to Dodd, musical works are norm-types "... that [admit] of properly and improperly formed tokens ..." and, moreover, are "... abstract, unstructured, and both modally and temporally inflexible ...."44 Davies argues, however, that these features of musical types prevent them from being audible in a sense with "... sufficient significance to merit the role assigned to audibility in determining the 'default' status of a musical ontology ..." and which also "... selectively [favours] the

\footnotetext{
37 Dodd (2008, p. 1118).

38 Dodd (2008, p. 1133, n. 9).

39 Dodd (2008, p. 1118).

40 Dodd (2007, p. 11).

41 Dodd (2008, p. 1128).

42 Dodd (2008, p. 1130).

43 David Davies (2009).

44 Dodd (2007, pp. 2, 4).
} 


\section{Dialogue}

type-token theory over its competitors. ${ }^{, 45}$ First, insofar as musical types are unstructured, “... all predications of particular acoustic properties of musical works, as types, have to be understood 'analogically.",46 For example, while a performance of a musical work can have "... the property of containing a particular occurrence of $\mathrm{G} \#$ at a particular moment during the performance-event ...," a musical type lacking the requisite temporal structure cannot; instead, it can only have an analogically related property such as that of "... requiring such a note in each of its correct instances." 47 But, once it is conceded that musical types have their particular acoustic properties only analogically, it is not clear how they can still be audible in a non-analogical sense. Davies puts the point as follows: “... how can something that possesses acoustic/sonic properties only analogically, and that lacks temporal parts, possess the general property of audibility in the same sense ... as its performances and playings?" the audibility of musical works in the analogical sense is, at bottom, simply a matter of having audible instances, any competing musical ontology will be able to easily secure the audibility of musical works in just the same fashion. As a result, the claim to a default status for the type-token model is unfounded.

Second, Dodd acknowledges that taking musical types to be abstract poses prima facie difficulties for the type-token model, given that hearing is a causal process and abstract entities are (putatively) causally inert. ${ }^{49}$ Dodd responds to this worry by arguing that, just as physical objects can be derivatively audible in virtue of playing the requisite causal roles in audible events, abstract musical types can enter into causal relations in a derivative sense that is sufficient for their audibility: “... [a] work of music ... can enter into causal relations derivatively by virtue of being a type of sound-event: a type whose token events can feature as relata of causal relations." ${ }^{50}$ However, Davies argues that, insofar as this derivative sense of audibility is the same as the analogical sense discussed above, for the same reasons audibility cannot be used to secure a default status for the type-token model. ${ }^{51}$ But, even if the derivative sense of audibility is distinct from the analogical sense, if musical types are norm-types, as Dodd would have it, then it is not clear that musical types are audible in this derivative sense. As Davies puts it, “... works, as norm types, do not in any obvious sense causally participate in events in virtue of their tokens in the way that cars causally participate in audible events." ${ }^{, 52}$

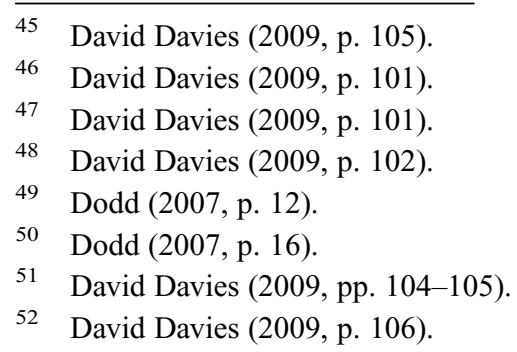


In my view, Davies' critique of Dodd's argument from audibility for the default status of the type-token model is well founded. But it's important to note that this critique is based on features possessed by musical types according to Dodd's specific version of the model, in particular, those of being abstract, being norm-types, and lacking structure. In order for the type-token model to yield a direct explanation of audibility, in terms of the ontological category of types alone, a tight connection between musical types and musical tokens needs to be sustained. Insofar as a substantial claim is made about the nature of musical types, a correspondingly substantial claim needs to be made regarding musical tokens (and vice versa). Dodd's difficulties arise from the fact that he makes a number of substantial claims regarding the nature of musical types that they are abstract, normative, and structureless - without making corresponding claims about their tokens, and instead simply taking it for granted that their tokens are their performances. The upshot is that Dodd's version of the type-token model fails to sustain the kind of connection between musical types and tokens required by his own argument.

Nevertheless, an advocate of the type-token model might reject Dodd's version of the view in favour of a variant that avoids Davies' objections, perhaps by taking musical types to share structural features with their token performances and to be non-normative. And the result might be a theory that retains a sufficiently tight connection between musical types and tokens to yield the kind of direct explanation of musical audibility that supports the default status claimed for the type-token model. Rather than attacking the claim of a default status for the type-token model vis-à-vis audibility directly, the central argumentative strategy in what follows is to concede this default status, for the sake of argument, and show that the continuity relation enables the continuant-stage model to offer an explanation of musical audibility that piggybacks on the direct explanation putatively offered by the type-token model. The upshot of this argument is that the phenomenon of audibility provides no basis to favour the type-token model over the continuant-stage model.

\section{Musical Continuity}

\subsection{Continuity Relations}

As above, the role of the continuity relation within the continuant-stage model is to determine which musical performances are I-Instances of which musical works. ${ }^{53}$ The first thing to note is that the continuity relation is a temporal relation, in the sense that a requirement for an event, $b$, to stand in this relation to an event, $a$, is that $b$ occur subsequently to $a$. As a result, the continuity relation is neither reflexive nor symmetrical: after all, not only can no event be subsequent to itself, no event can be both subsequent to and prior to another event. This distinguishes the continuity relation from similarity relations, which are normally

53 See Alward (2004, p. 334); Caplan and Matheson (2006, p. 62). 
understood to be both reflexive and symmetrical. ${ }^{54}$ In an earlier account of the continuity relation, I took both relata of the relation to be performances. ${ }^{55}$ Moreover, I argued that in order for a later performance to be continuous with an earlier performance it has to both share central melody lines with the earlier performance and be the product of an intention to produce an arrangement or interpretation of the earlier performance rather than an intention to create a new work. ${ }^{56}$ So, for example, Young's performance of Rockin' in the Free World on April 15, 2009 in Lethbridge, Alberta is continuous with his performance of Rockin' in the Free World on October 18, 2008 in Regina, Saskatchewan, according to my earlier view, only if the later performance shares central melody lines with the earlier performance and Young intended the later performance to be an interpretation or arrangement of the earlier one.

There are, in my view, two central reasons to balk at this earlier version of the continuity relation. First, the decision to formulate the continuity relation so that both relata are performances was based on the assumption that this relation is transitive, that is, that if an event, $b$, is continuous with an event, $a$, and an event, $c$, is continuous with $b$, then it follows that $c$ is continuous with $a$, even if $c$ is not directly continuous with $a$ independently of its relation to $b$. However, I am no longer convinced that the continuity relation is transitive because I suspect that the cumulative effect of the permissible differences between its relata will ultimately yield a new musical work. Suppose, for example, that Rockin' in the Free World was created by means of a score and that Young's performance of it on October 18, 2008 in Regina, Saskatchewan deviated as substantially from the score as permitted by the continuity relation, and his performance April 15, 2009 in Lethbridge, Alberta deviated from the Regina performance to the same degree. If the continuity relation is transitive, then the Lethbridge performance would have to count as a performance of the scored work, despite its perhaps substantial deviations from the score; but my current inclination is to suppose the contrary is true, at least in some cases. Second, the requirement that a performance share central melody lines with any prior event it is continuous with was meant to be a one size fits all condition for performances in all musical genres and all musical-historical contexts, applying equally to eighteenth century classical music and contemporary jazz. But, given that permissible performance deviations from the work-as-composed vary with both the musical genre and the musical-historical context at issue, any unitary requirement will likely be too restrictive in some cases and too permissive in others.

In light of these worries, a revised version of the continuity relation will be developed here. There are, however, a number of preliminary issues that need to be addressed up front. First, the relata of this revised relation will be taken

\footnotetext{
54 See, e.g., Mag Uidhir (2013, p. 179).

55 Alward (2004, p. 334).

56 Alward (2004, p. 334).
} 
to be the scores, performance-exemplars, and recordings by means of which musical works are created, on the one hand, and performances, on the other; that is, a performance can be continuous with either a work-generating score or performance-exemplar, and insofar as it is so, it counts as in I-Instance of the work in question. ${ }^{57}$ Of course, playings of recordings can also count as I-Instances of a musical work as long as they are produced by suitable decoding devices - turntables, cd players, ipods, or what have you — that are operating within normal parameters. The focus here, however, will be on performances. Second, the continuity relation between scores or performance-exemplars, on the one hand, and performances, on the other, will provisionally be taken to be mediated by musical types. ${ }^{58}$ The prospects for reformulating the view without appeal to types will be addressed below. Now, by themselves, neither scores nor performance-exemplars uniquely determine particular sound-pattern types. After all, not all musical features identified by a score or present in a performance-exemplar are essential to, or constitutive of, the musical work in question. One approach here might involve an appeal to composer intentions; but, at least insofar as one believes that a musical work does not come into existence until a score, recording, or exemplar is produced, one is committed to giving these items some kind of primacy over compositional intentions. As above, a better approach would be to invoke notational and performance practices, genre conventions, and various sorts of listening practices from the musical-historical context in which the work was produced; and to the extent that such practices, together with the scores or exemplars in question, fail to determine unique sound-pattern types, compositional intentions can be deployed as tie-breakers. ${ }^{59}$ Third, musical performances will be treated here as the products of performance plans. A performance plan is a plan to produce a pattern of sounds, normally by means of the use of specific musical instruments. It can consist of a detailed scored arrangement, the collective performance intentions of the various players, or even the sum of the transient mental states of an improvising instrumentalist. And, given that a plan of this kind can, in principle, be performed on multiple occasions, it can be taken to determine a sound-pattern type.

57 Insofar as a composer creates multiple versions of a musical work - perhaps by producing more than one score for it - a performance counts as an I-Instance of the work if it is continuous with (at least) one version.

58 If someone wants to perform a musical work created by a recording, she will presumably have to base the performance on a playing of the recording. Arguably, in such circumstances, the playing of the recording plays a similar role to that of an exemplar $v i s-\grave{a}$-vis the performance in question. As a result, we can reasonably subsume this case under that of continuity between performances and exemplars.

59 This is meant to be reminiscent of the moderate actual intentionalist position in the art interpretation literature. See, e.g., Stecker (2006). 
In order for a performance to stand in the (revised) continuity relation to a score or performance-exemplar, it has to satisfy two conditions: an intentional condition and a correspondence condition. The intentional condition simply requires that the performance be intended as a performance of the work composed by means of the score or performance-exemplar. The point of this condition is twofold: first, it rules out the possibility of accidentally performing a musical work by means of a performance that just so happens to correspond to the work in the right way; and second, it enables us to distinguish performances of a given work from performances of distinct but derivative works. The correspondence condition is somewhat more complex. It requires a certain degree and kind of conformity between the sound-pattern type determined by the score or performance-exemplar and the type determined by the performance plan: at its strongest, it might require an exact correspondence between these sound-pattern types; at its weakest, the work-as-composed might place no constraints on the performance plan whatsoever. ${ }^{60}$ In my view, there is no uniform degree and kind of conformity required across all musical genres and all musical-historical contexts. Rather, the performance traditions of different musical genres in different times and places allow differing ranges of flexibility in performance plans. And, as long as performance plan falls within the range of flexibility permitted by the performance tradition governing the work in question at the time of the performance, it satisfies the correspondence condition. Consider again Young's work Rockin' in the Free World, which, let us suppose, was composed by means of a written score. According to the revised view, Young's performance on October 18, 2008 in Regina, Saskatchewan stands in the continuity relation to said score just in case Young intended it to be a performance of Rockin' in the Free World and the performance plan fell within the range of flexibility vis-à-vis the score permitted by the performance tradition in rock music at the time of the performance (i.e., October 18, 2008). ${ }^{61}$

\subsection{Continuity and Audibility}

Recall: Dodd has argued that taking musical works to be sound-pattern types yields a direct explanation of their audibility in terms of their ontological category, which gives the type-token model a default status with respect to the question of musical ontology. In this section, I will argue, contra Dodd, that the very same explanation is available to advocates of the continuant-stage

60 An advocate of the type-token model would, presumably, find the former quite amenable; Kaplan (1990, p. 105) advocates something along the lines of the latter in his account of the continuity relation for words.

61 In the case of a new musical genre, the permissible range of flexibility will be determined by the critical and appreciative practices that develop alongside it. Prior to the development of these practices, however, there may be no fact of the matter whether or not a given performance stands in the continuity relation to a scored work. 
model and, hence, that Dodd's view gains no advantage on this front. The argument here has two stages. First, if Dodd is correct and appreciators can hear sound-pattern types by listening to their tokens, then by listening to a performance that is the product of a given performance plan, appreciators can hear the sound-pattern type determined by said plan. And second, insofar as a performance plan meets the correspondence condition, it identifies an acceptable way of performing a given musical work. As a result, by way of hearing the soundpattern type determined by some such plan, appreciators thereby hear the work. Consider again Young's performance on October 18, 2008 in Regina, Saskatchewan: according to Dodd's view, concert-goers could hear the soundpattern type determined by the performance plan by means of listening to the performance; and insofar as the plan met the correspondence condition, these concert-goers would thereby hear Rockin' in the Free World itself.

As should now be clear, this explanation of audibility on the continuant-stage model is neither ad hoc nor ontologically profligate, as least when compared to the type-token model. As we have seen, the continuity relation on which it relies is independently motivated by the need to determine which musical performances are I-Instances of which musical works. Moreover, it invokes no controversial entities beyond the sound-pattern types it shares with the type-token model. Nevertheless, there are a couple of worries about this argument worth considering here. First, one might argue that, even if a performance plan meets the correspondence condition, if the performers fail to adequately implement the plan — by playing a large number of incorrect notes, for example then appreciators will fail to hear the work by listening to the performance. This worry is well founded but yields no advantage to the type-token model: since not all performances of a work are tokens of the relevant sound-pattern type, not all performances facilitate aural access to the work even on the type-token model. ${ }^{62}$ Moreover, a simple solution to this worry can be had by claiming that a musical work can be heard only by listening to those performances that are tokens of the sound-pattern type determined by the performance plan or perhaps, borrowing from Levinson, those performances that are intended to conform to the plan and succeed to a reasonable degree. ${ }^{63}$ And, second, one might argue that adopting an ontology of types within the continuant-stage model undercuts any motivation for favouring this view over the simpler type-

62 One could, of course, insist that only sound events that are tokens of the requisite type count as performances of the work at all. But not only does this deviate from the ordinary sense of 'performance,' it doesn't so much resolve the worry as change the terminology in which it is framed.

63 Levinson (1980, p. 24). I am assuming that performances (i) that are the products of performance plans that satisfy the correspondence condition but (ii) which fail to (sufficiently) successfully conform to those plans can nevertheless be I-Instances of the works in question. 
token model. But, as noted above, three separate motivations for the continuantstage model have been defended: ontological parsimony, musical flexibility, and creatability. ${ }^{64}$ As a result, even if invoking sound-pattern types undermines the first motivation for the view, the other two remain in play.

Finally, one might balk at the account of musical audibility on offer here on the grounds that any theory of musical works that invokes types is committed to an unpalatable Platonic ontology. Leaving aside the question of whether an adequate nominalist account of types is in the offing, the first thing to note is that this is clearly not a complaint that an advocate of the type-token model could raise; moreover, given that the central goal of this paper is to establish that the typetoken model has no advantage over the continuant-stage model vis-à-vis the phenomenon of musical audibility, this worry poses no difficulties for the argument on offer here. Nevertheless, it is worth sketching how the view developed here might be adapted to secure the audibility of musical works without appeal to sound-pattern types. One approach would be to note that, although performance plans might well determine sound-pattern types, they have as their goals particular sound-event tokens. As a result, we might take performance intentions to have sound-event tokens as their intentional objects. And, if we do so, we can redefine the correspondence condition so that it requires a certain degree and kind of conformity between a score or performance-exemplar and the sound-event token that the performers intend to produce. Moreover, insofar as the actual performance is sufficiently similar to the intended performance, a case can be made that appreciators can hear the latter by listening to the former. This is, of course, only the barest of sketches, but it is sufficient to show that there is a plausible account of musical audibility that does not invoke musical types on the continuant-stage model.

\section{Conclusion}

Dodd's claim that the type-token model has a default status as an account of musical ontology — due to its ability to provide a direct explanation of the audibility of musical works in terms of the ontological category to which they belong - has proven to be ephemeral. As we have seen, David Davies has provided good reasons to suppose that, given the details of Dodd's account of musical types, no such direct explanation of musical audibility is forthcoming on the type-token model. And I have shown how the continuity relation - which is independently required to determine which musical performances are I-Instances of which musical works - can be deployed to yield an equally strong explanation of musical audibility as that proffered by its competitor. Any advantage for the type-token model over the continuant-stage model will have to be found elsewhere.

64 Caplan and Matheson (2006); Rohrbaugh (2003, p. 178); Alward (2004, pp. 331332). 
One might worry that this response to Dodd is inadequate as it stands. The trouble is that, insofar musical performances are just individual stages in the histories of persisting musical works, as the continuant-stage model would have it, appreciators cannot hear all of a work by listening to a single performance of it. Dodd puts the point as follows: "Perdurantism's problem is that it seems to entail the absurd thesis that works of music cannot be heard in toto." 65 There are, however, three distinct and compelling replies that can be offered on behalf of the continuant-stage model here. First, the argument presupposes that musical works persist by perduring - that is, by having temporal parts that exist at every time the work exists. But an advocate of the continuant-stage model might instead reasonably endorse an endurantist account of persistence according to which works persist by being multiply located in time - and avoid the objection altogether. ${ }^{66}$ Second, one might concede that compositions persist by perduring and argue that, even so, the sonic properties the experience of which are sufficient for hearing a complete musical work are all present during any single (sufficiently well-played) performance of it. And, third, one might argue that Dodd's argument against perdurantism relies on specious assumptions about the relationship between metaphysical theories of persistence and common sense platitudes about what is required to hear all of a musical work. But that is a story for another time. ${ }^{67}$

\footnotetext{
65 Dodd (2008), p. 1129.

66 See, e.g., Tillman (2011), p. 29. Dodd (2008, p. 1126) writes approvingly of endurantism as a solution to the objection at issue, although he argues that it falls prey to other equally decisive difficulties.

67 Alward (forthcoming).
}

\section{References}

Aliyev, Alexey

2017 "Musical Perdurantism and the Problem of Intermittent Existence." Grazer Philosophische Studien 94(1-2): 83-100.

Alperson, Philip

1984 "On Musical Improvisation." Journal of Aesthetics and Art Criticism 43(1): 17-29.

Alward, Peter

2004 "The Spoken Work." Journal of Aesthetics and Art Criticism 62(4): 331-337.

Alward, Peter

Forthcoming "Musical Ontology and the Question of Persistence." Acta Analytica. https://doi.org/10.1007/s12136-019-00398-w.

Caplan, Ben, and Carl Matheson

2006 "Defending Musical Perdurantism.” British Journal of Aesthetics 46(1): $59-69$. 
Cray, Wesley

2016 "Unperformable Works and the Ontology of Music." British Journal of Aesthetics 56(1): 67-81.

Currie, Gregory

1989 An Ontology of Art. London: St. Martin's Press.

Davies, David

2009 "Dodd on the "Audibility' of Musical Works." British Journal of Aesthetics 49(2): 98-108.

Davies, David

2010 "Multiple Instances and Multiple 'Instances." British Journal of Aesthetics 50(4): 411-426.

Davies, Stephen

2003 "Ontology of Art," in Oxford Companion to Aesthetics, edited by Jerrold Levinson. Oxford: Oxford University Press, pp. 155-180.

Dodd, Julian

2002 "Defending Musical Platonism." British Journal of Aesthetics 42(4): $380-402$.

Dodd, Julian

2004 "Types, Continuants, and the Ontology of Music." British Journal of Aesthetics 44(4): 342-360.

Dodd, Julian

2007 Works of Music: An Essay in Ontology. Oxford: Oxford University Press.

Dodd, Julian

2008 "Musical Works: Ontology and Meta-Ontology." Philosophy Compass 3(6): 1113-1134.

Friedell, David

Forthcoming "Why Can't I Change Bruckner's Eighth Symphony?" Philosophical Studies. https://oi.org/10.1007/s11098-0181207-3.

Kania, Andrew

2006 "Making Tracks: The Ontology of Rock Music." Journal of Aesthetics and Art Criticism 64(4): 401-414.

Kania, Andrew

2013 "Platonism vs. Nominalism in Contemporary Musical Ontology," in Art and Abstract Objects, edited by Christy Mag Uidhir. Oxford: Oxford University Press, pp. 197-212.

Kaplan, David

1990 "Words." Proceedings of the Aristotelian Society: Supplement 64: 93119.

Kivy, Peter

1983 "Platonism in Music: A Kind of Defense." Grazer Philosophische Studien 19(1): 109-129. 
Levinson, Jerrold

1980 "What a Musical Work Is." The Journal of Philosophy 77(1): 5-28. Mag Uidhir, Christy 2013 Art and Art-Attempts. Oxford: Oxford University Press.

Rohrbaugh, Guy

2003 “Artworks as Historical Individuals.” European Journal of Philosophy 11(2): 177-205.

Stecker, Robert

2006 "Moderate Actual Intentionalism Defended." The Journal of Aesthetics and Art Criticism 64(4): 429-438.

Tillman, Chris

2011 "Musical Materialism." British Journal of Aesthetics 51(1): 13-29. 